
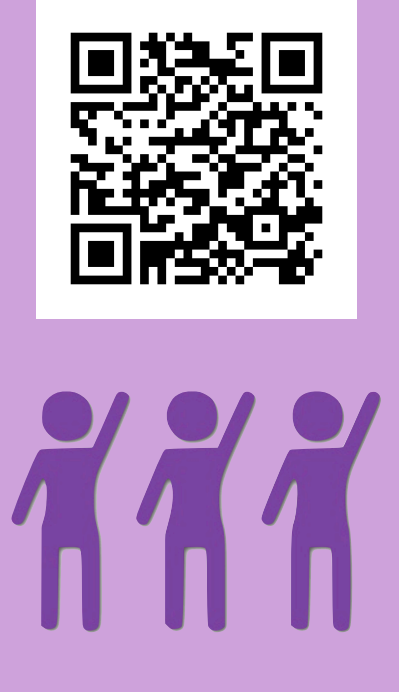

\title{
Contribuições da antropologia para formação de estudantes de medicina durante o módulo de obstetrícia
}

\section{Fernanda Beatriz MACIEL,Universidade Federal da Bahia}

Hebert Luan Pereira Campos dos SANTOS, Universidade Federal da Bahia Paulo Rogers FERREIRA, Universidade Federal da Bahia

Este relato de experiência visa contribuir para uma reflexão sobre o contexto da formação em obstetrícia, enquanto área integrante da graduação médica, instigada à luz da introdução da antropologia no processo de aprendizagem. Para alcançar este objetivo, decidiu-se dividir este artigo em seções. A primeira tratou do processo de inserção da antropologia durante a formação dos discentes em medicina no semestre que possui como eixo temático Concepção e Nascimento, refletindo sobre os desafios que envolvem o aprender a relativizar práticas que se alicerçam na Medicina Baseada em Evidências (MBE). Posteriormente, em uma segunda seção, foram discutidas as reflexões suscitadas por uma experiência vivenciada durante atividade prática com um grupo de mulheres que luta pelo parto humanizado e maternidade ativa. Por fim, em uma última seção, foi apresentada a possibilidade de uma reorientação do olhar sobre os aspectos culturais que envolvem a concepção, o nascimento, a mulher e o seu corpo.

PALAVRAS-CHAVE: Obstetrícia. Educação Superior. Recursos Humanos em Saúde. Antropologia. Parto Humanizado. 


\section{Introdução}

A história do parto e do nascimento vem sendo transformada de maneira progressiva, trazendo questionamentos e abrindo possibilidade de discussões, tão necessárias, a respeito da mudança nas condutas implementadas no ciclo gravídico-puerperal, os quais refletiram e refletem diretamente sobre a formação médica (VENDRÚSCOLO; KRUEL, 2016).

Nos últimos anos existiram grandes movimentos políticos e educacionais no sentido de transformar a formação dos profissionais médicos. As Diretrizes Curriculares Nacionais (DCNs), que norteiam a organização do ensino de Medicina e constituem-se como documento fundamental para auxiliar os responsáveis pelos programas de ensino, determinam que a Ginecologia e a Obstetrícia (GO), juntamente com a Clínica Médica, Cirurgia, Pediatria, Saúde Coletiva e Saúde Mental, componham as seis grandes áreas de aprendizado no ensino médico (BRASIL, 2014).

Por parte das escolas médicas, existe um esforço em iniciar o aprendizado da Ginecologia e da Obstetrícia já no início do curso, realizando estágios no meio do curso e culminando com o internato ao final dos quatro últimos semestres, tornando esse ensino eminentemente prático. A ideia é que este estudo prático permita ao aluno o aprendizado, com visão de médico generalista, das condições fisiológicas e patológicas mais comuns da mulher durante o ciclo de vida, desde a infância ao climatério e pós-menopausa. A ênfase é centrada na prevenção, no diagnóstico, no tratamento e no prognóstico das principais afecções ginecológicas e obstétricas (RAMOS, 2015).

Diversos autores referem que a formação médica, durante a graduação e as residências, contribui amplamente para disseminação da violência institucional nos serviços de atenção à saúde da mulher no Brasil (GUIMARÃES et al., 2018; PALHARINI, 2017; RODRIGUES et al, 2018; ALONSO, 2018). Os efeitos da hermenêutica relação de saberpoder entre estudantes de medicina e as mulheres atendidas; a baixa prioridade dada à aprendizagem das disciplinas em saúde coletiva e de aptidões associadas à comunicação são alguns dos elementos do ensino e treinamento em serviços de atendimento à mulher que contribuem para uma série de violências e violações ao corpo feminino e as suas feminilidades (HOTIMSKY, 2009). 
Nesse sentido, o presente artigo visa contribuir para uma reflexão sobre o contexto da formação em obstetrícia, enquanto área integrante na graduação médica, instigada à luz da introdução da antropologia no processo de ensino-aprendizagem. Para alcançar este objetivo, decidiu-se dividir este artigo em seções. A primeira tratará do processo de inserção da antropologia durante a formação dos estudantes de medicina no semestre que possui como eixo temático Concepção $e$ Nascimento, refletindo sobre os desafios que envolvem o aprender a relativizar práticas que se alicerçam na Medicina Baseada em Evidências $^{1}$ (MBE). Posteriormente, em uma segunda seção, as discussões e reflexões suscitadas por uma experiência vivenciada durante atividade prática com um grupo de mulheres. Por fim, em uma última seção, algumas considerações às quais a construção deste trabalho suscitou.

\section{Inserção da Antropologia na Formação Médica}

O parto e o nascimento ao serem compreendido pela clínica médica e pela obstetrícia, envolvem para além da perspectiva fisiológica do evento, dimensões que integram o seu caráter ritualístico e conotam seu completo significado cultural mediante os grupos sociais, retroalimentados por uma conjuntura sociocultural (MALHEIROS et al, 2012). Desde o final do século XVIII, o corpo da mulher grávida passou a ser foco dos médicos, sendo o parto e a gravidez assuntos que só ganharam relevância com a entrada do médico em um domínio que até então tinha sido exclusivo das mulheres. Contudo, apesar da expansão da clínica médica e do processo de medicalização que se estabeleceu em diversos países, o domínio da parturição foi o último e mais difícil de ser conquistado pela equipe médica, desde então verifica-se a apropriação do parto como um evento técnico embasado no aparato médico (MARTINS, 2005; TORNQUIST, 2004).

\footnotetext{
$1 \mathrm{MBE}$ se traduz pela prática da medicina em um contexto em que a experiência clínica se integra com a capacidade de analisar criticamente e aplicar de forma racional a informação científica de forma a melhorar a qualidade da assistência médica. Deste modo, a prática da MBE requer a identificação dos problemas relevantes ao paciente; a conversão dos problemas em questões que conduzam às respostas necessárias; a pesquisa eficientemente as fontes de informação; avaliação da qualidade da informação e a força da evidência dessas, favorecendo ou negando o valor de uma determinada conduta, conclusão e aplicação das conclusões dessa avaliação na melhoria dos cuidados prestados aos pacientes (LOPES, 2000).
} 
Neste âmbito, a adoção de práticas que tornam coadjuvante o papel das parturientes no evento do parto passa a ser justificadas à medida que a obstetrícia médica institucionalizou o nascer e se reconheceu como resgatadora das mulheres por passar a ofertar um parto sem dor, utilizando de recursos por muitas vezes desconhecidos pelas gestantes, mas cuja empregabilidade não se questionava ao considerar as atribuições finais (PEREIRA; FRANCO; BALDIN, 2011).

O parto desde então passou a ser concebido como uma forma de violência intrínseca, uma vez que a parturiente passou a ser submetida a procedimentos desnecessários e sua autonomia deixou de ser respeitada, e tido, essencialmente, como um fenômeno "fisiologicamente" patogênico, que requeria diferentemente de outrora um acompanhamento hospitalizado, medicalizado e passível de intervenção cirúrgica. Em contrapartida, em meio a essa conjuntura emergiu um conceito de humanização do nascer na prática médica com base em ideais propostos pela Organização Mundial de Saúde (OMS), bem como pelo Ministério da Saúde e alguns órgãos não governamentais que recriou e reformulou a ideia de autonomia do corpo feminino, em consonância com o preconizado pela Política Nacional de Humanização da atenção e da gestão na saúde (BRASIL, 2004). Recai, portanto, na construção da ideia de um parto humanizado, cabendo, assim, à pergunta: mas que parto humanizado é este? É um parto que ainda é calcado por práticas que se fundamentam a partir da MBE que legitima e perpetua violências sobre o corpo feminino e sobre as feminilidades, uma vez que muitas das vezes fica a cargo do profissional decidir o que se faz melhor para o evento do parto-nascimento sem repensar, refletir e reavaliar sobre as melhores condições do ponto de vista psicocultural, respeitando os seus direitos das parturientes e seu protagonismo em todo o processo do nascimento (PEREIRA; FRANCO; BALDIN, 2011).

Frente a isso, o que se coloca é que esse parto humanizado seja incumbido primordialmente do respeito às decisões da mulher (valores $\mathrm{e}$ preferências do paciente), de forma que ela possa escolher, frente ao conhecimento da sua condição de parto, a melhor forma de conceber de modo dialogado e horizontal com o profissional médico que a acompanha, podendo ambos recorerrem à MBE para adquirirem maiores esclarecimento sobre os benefícios de cada via de parto e outras informações que sejam necessárias para a sua realização (MOURA, 2009). 
Existe, assim, um discurso sobre esse "nascer humanizado" que circunscreve nas corporalidades da mulher grávida uma concepção de protagonismo do evento. A MBE, por sua vez, se figura de conhecimentos técnicos e científicos sistematizados que comprovam e tornam válidas tais necessidades de práticas ditas humanizadas de assistência ao parto e nascimento. É dentro desta seara que a inserção da antropologia, através da relativização e da interculturalidade na saúde, pode auxiliar no questionando, relativização ou sistematização de tal discurso. Sendo assim, cabe a questão: Como possibilitar que as práticas consideradas humanizadas que se amparam na MBE também sejam objeto de análise e crítica dos estudantes de medicina?

Ao considerar o caráter multidimensional envolto de signos e significados nas esferas corporais, temporais, psíquicas e culturais que transpassam a concepção de saúde e doença, em especial, o parto e o nascimento, é que o curso de medicina do Instituto Multidisciplinar em Saúde (IMS) da Universidade Federal da Bahia (UFBA) introduziu, na tentativa de melhor elucidar aos seus graduandos esses aspectos, o ensino de antropologia na sua matriz curricular. É válido considerar que a matriz curricular surge após análise sistemática dos currículos dos cursos de medicina das instituições de ensino superior do Brasil levando em consideração a urgência na transformação cultural da formação médica (UFBA, 2015).

Para enfrentar o desafio de um desenho curricular inovador, pautado em metodologias ativas, e consonante com o disposto nas Diretrizes do Ensino Médico no Brasil, o IMS/UFBA propõe um currículo integrado e híbrido, que busca aproveitar tanto as vantagens do modelo curricular tradicional como das metodologias ativas, fundamentado na interdisciplinaridade e na transdisciplinaridade. Caracteriza-se por não seguir o processo pedagógico tradicional e se fundamenta na abordagem centrada no aluno por meio das metodologias ativas, inserção precoce nos campos de prática e serviços de saúde. O curso busca desenvolver o propósito da formação qualificada de médicos com perfil generalista capaz de atuar com responsabilidade social nas diversas áreas onde a medicina se constitua (UFBA, 2015).

Dentro do eixo temático Concepção e Nascimento, para além das disciplinas que compõem o campo da saúde e da saúde coletiva, a antropologia fez-se mister nesse cenário, pois em seu ínterim tem por reflexão a relação humana em uma perspectiva comparativa, de modo que reconheça e respeite a diversidade de soluções que as diversas 
culturas têm construída no intuito de explicar e atender o que se concebe culturalmente como saúde e doença. Sobretudo, a inserção dessa área de conhecimento endossa os saberes adquiridos pelos futuros profissionais ao longo do curso de modo a possibilitar a noção de relativismo cultural frente às concepções e práticas de saúde, estas que também exprimem uma cultura, a cultura biomédica (MOURA, 2009).

No tocante as disciplinas clínicas, a formação dos estudantes de medicina se dá através da inserção nos serviços de saúde, principalmente, públicos em que os usuários são, em sua maioria, pobres e de minorias étnicas para realizar o treinamento de habilidades técnicas. Há um processo de coisificação dos corpos por muitos profissionais de saúde, sobretudo médicos, que se transformam em objeto de treinamento "[...] sem que abusos, como intervenções desnecessárias ou não recomendadas, maus-tratos, desrespeito e suas consequências sejam reconhecidos como violações de direitos" (MARRERO; BRÜGGEMANN, 2018).

Corroborando com a existência de tais práticas, Hotimsky (2009) elucida em seu estudo etnográfico que as instituições de ensino médico são espaços privilegiados para a aprendizagem e perpetuação dessas práticas de violação da integridade física das mulheres e de seus direitos humanos. Ressalta-se que uma discussão profunda e inter/ multidisciplinar acerca da formação dos estudantes de medicina durante o módulo de obstetrícia pode corroborar na reformulação de um novo modelo cultural intervencionista, diríamos, um etnomodelo, enaltecendo dentre as tecnologias e evidências possíveis práticas de atenção que valorizem as concepções e as práticas de acompanhamento e aconselhamento no parto e nascimento almejados pelos integrantes que o vivencia, compreendendo o seu papel profissional como o de facilitador do processo (TORNQUIST, 2004). Cabe considerar que as relações assimétricas que se estabelecem entre profissional e a mulher durante o parto, marcadas muitas vezes pelo autoritarismo profissional, são construídas ainda no processo de formação profissional vigente, que favorece a manutenção de hierarquias sociais e raciais. 


\section{Relativização da Compreensão do Parto e Nascimento}

Com o objetivo de fazer uma análise à luz da antropologia e baseando-se em suas técnicas de estudo, nesta seção serão descritas as reflexões suscitadas pela experiência vivenciada através do contato com integrantes de uma roda de gestantes, gestantes estas que residem no sudoeste baiano, um grupo cujo escopo de discussão se baseia na experiência compartilhada da gravidez e na promoção do chamado "parto natural humanizado", alicerçado na MBE.

A coleta de dados foi norteada por pesquisa documental, etnografia rápida ${ }^{2}$ e entrevistas semiestruturadas realizadas junto ao grupo, como proposta de estudo de um dos componentes curriculares do semestre. Tais momentos se desenvolveram em dois contextos: na sala de aula e em reuniões com o grupo de apoio ao parto humanizado e maternidade ativa supramencionado.

Em primeira análise, observamos que o grupo possui como alicerce a defesa pelo chamado "parto humanizado", cujos critérios de elegibilidade e características específicas estão previamente estabelecidos em literaturas científicas e registros legais como sendo aqueles que, grosso modo, fazem uso mínimo de intervenções médicas e farmacológicas possíveis ou o que respeita o tempo físico e psíquico de cada mulher para parir em ambiente respeitoso e acolhedor e com seu consentimento informado para todo e qualquer procedimento realizado. Desta forma, as integrantes do grupo em questão se valiam de referências-base para guiarem o prosseguimento da reunião, na qual os componentes antes mesmo de participarem já eram expostos ao que era considerada, por elas, a finalidade de discussão da roda, mesmo que essa "discussão" se voltasse para a verdade delas. Assim, os recursos científicos são utilizados como estratégia para exaltação do próprio discurso e como mecanismo para mitigar refutações.

Nesse ínterim, José Ricardo Ayres (2007) traz uma reflexão acerca da limitação trazida em consequência às delimitações conceituais

2 A etnografia rápida se define por uma curta estadia em contextos culturais sob investigação, porém se utilizando, de forma condensada, das técnicas da etnografia tradicional (observação, convívio com o contexto sob investigação, participação nos rituais deste contexto, etc.). Esta modalidade da etnografia é fundamental para estudantes de medicina que têm um prazo reduzido para desenvolverem trabalhos de campo quando de sua formação na prática médica na graduação. 
e polarização de dois estados bem conhecidos na área de saúde (saúde versus doença; saudável versus enfermo, etc.). Esta oposição, e fazendo uma analogia com Ayres, também se encontra entre o que seria a humanização e a desumanização, assim como há, muitas vezes, uma dicotomia entre o que é considerado saúde versus doença.

"A equivalência de saúde e doença como situações polares opostas de uma mesma natureza de fenômenos, identificados segundo uma mesma racionalidade, é tão limitante para a adequada compreensão dessas duas construções discursivas e das práticas a elas relacionadas, quanto negar as estreitas relações que guardam uma com a outra na vida cotidiana" (AYRES, 2007, p.01).

Ao se utilizarem de concepções bem situadas, o grupo de mulheres acaba por criar uma delimitação sobre a produtividade da reunião, cujos membros já estão previamente inseridos conceitualmente na realidade que se deseja defender, assim como há uma velada hostilidade etnocêntrica às concepções opostas. Por etnocentrismo, recuperamos o que diz Everardo P. Guimarães Rocha (1988) como sendo "uma visão do mundo onde o nosso próprio grupo é tomado como centro de tudo e todos os outros são pensados e sentidos através dos nossos valores, nossos modelos, nossas definições" (ROCHA, 1988, p. 5).

Considerando o etnocentrismo como uma visão de mundo definida a partir de valores culturais particulares, nota-se, nesta roda de gestantes que aqui investigada, um universo etnocêntrico no tocante ao evento parto na vida da mulher, construído a partir de suas concepções e significando-o com ênfase na positividade do chamado "parto natural humanizado". Este universo é composto pela crença na MBE, por ritos discursivos enaltecendo o "cientificamente comprovado", por citações de autores previamente selecionados e por elogios ao humanizado. Nesse aspecto, percebe-se uma preocupação em difundir o conhecimento científico nas rodas de discussões, na tentativa de preparar as participantes para o processo de gestação, parto e puerpério, ao passo em esta conscientização centrada no cientificismo é definida como "empoderamento" pelas organizadoras da roda. Embora o respeito às ideias e desejos distintos dos preconizados pela MBE sempre prevaleça durante os diálogos, é notória a presença de vieses no tocante aos temas e suas estratégias de abordagem, de modo que, ainda que o objetivo primordial do grupo seja o de "esclarecimento", ocorre, inevitavelmente, uma tendência nas pessoas ali inseridas, com base em uma vertente preconcebida. Logo, ao mesmo tempo em que se viabiliza o acesso à 
informação, as participantes e os participantes presentes na roda, pois em muitos casos o marido as acompanha, são afetados por um conceito de saúde ali preconizados.

Sobre o caráter humanitário apregoado pelas organizadoras da roda e seu poder de persuasão para com os as participantes e os participantes este evento, podemos traçar um paralelo com o conceito de cruzadas morais elucidado por Becker (1985). Este autor argumenta que uma cruzada moral começa, muitas vezes, por uma "forte motivação humanitária”. A consequência desta cruzada moral que começou, por exemplo, com uma campanha para "melhorar a qualidade de vida das mulheres na hora do parto", seria, por fim, a criação de um novo conjunto de leis, o que acarretaria em uma nova legislação, estabelecendo um novo dispositivo de instituição, formando e contratando pessoal especializado para aplicar esta lei e, posteriormente, engajando a polícia para conter, e muitas vezes prender, os casos desviantes desta lei.

São, muitas vezes, as instituições existentes que se responsabilizam pela administração da nova lei, mas é mais frequente a criação de um quadro novo de pessoal especializado [...]. Com a execução destas organizações especializadas, a cruzada se institucionaliza. $\mathrm{O}$ que se iniciou como uma campanha para convencer o mundo da necessidade moral de uma nova norma transforma-se, finalmente, em uma organização destinada a fazer respeitá-la. (BECKER, 1985, p. 179, tradução nossa)

Em paralelo com o grupo das mulheres que defendem o chamado parto normal humanizado, o que começou com um desejo inicial de "esclarecimento" às mulheres grávidas sobre violência obstétrica nas rodas se tornou a lei No. XXXX/XX3, sancionada pelo Diário Oficial de um município do sudoeste baiano, tornando a violência obstétrica passível de punição também de acordo com aparatos municipais. No

3 Para preservar o anonimato da fonte, o número da Lei mencionada, como o nome do município, foram excluídos. 
mais a criação de uma especialidade chamada doula 4 . Compreende-se que esse grupo, não obstante dos demais grupos de caráter humanitário, constituem-se em processos de cruzada moral. Dessa forma, a união dos envolvidos na coletividade em questão corrobora para ascensão de um novo mundo cultural com suas regras, ritos, itinerários, crenças e interditos que perante a lógica científica, humanitária, ativista, punitiva, favoreceu o desenvolvimento de pilares construtivistas que dessem relevância e aceitabilidade aos argumentos desenvolvidos e socializados, estes etnicamente centralizados. Ora, ao longo da história de fundação deste grupo foram instituídos valores e táticas específicas de alcance de atributos específicos, que nesse caso se conceberiam através da promoção de um certo modelo etnocêntrico de parto.

\section{Considerações Finais}

A formação médica atual, assim como a obstetrícia enquanto eixo integrante, encontra-se estruturada a partir de um modelo tecnocientífico. No entanto, surgem propostas orientadas por um projeto ético que tenciona esse modelo com vistas à sua transformação. A utilização da MBE se valida na construção de um discurso que legitima as práticas médicas, nesse sentido, a inserção da antropologia trouxe uma perspectiva não só crítica, mas sobretudo no sentido de relativizar culturalmente tais práticas.

A instituição de novos cenários de prática na formação médica, através da inter e multidisciplinaridade, aqui transcritos através da vivência da experiência do estudo antropológico na graduação médica de estudantes do curso de medicina do Instituto Multidisciplinar de Saúde da Universidade Federal da Bahia (IMS/UFBA), no módulo obstetrícia, possibilita uma reorientação do olhar sobre discursos etnicamente centralizados sobre "parto" e sobre "humanização" como também sobre o papel cultural do médico, dele ser ou não "humanizado", da ciência, à

4 Para Barbosa, Herculano, Brilhante e Sampaio (2018, p. 421): "A palavra 'doula' tem origem grega e significa 'mulher que serve'. Hoje, refere-se à pessoa que dá suporte emocional à mulher intraparto, com treinamento específico sobre fisiologia do parto normal, métodos não farmacológicos para alívio da dor, cuidados pós-natais e aleitamento materno [...] Nesse contexto, a doula costuma ser exaltada por integrantes do movimento pela humanização do parto e do nascimento, principalmente por sua atuação no Sistema Único de Saúde (SUS) [...] Nessa mesma direção, a inserção da doula é considerada uma das boas práticas incentivadas pela Política Nacional de Atenção Obstétrica e Neonatal, estabelecida em 2005”. 
invenção ritualística de discursos e procedimentos sobre o corpo da mulher grávida, referente à temática da concepção e nascimento.

Este estudo não buscou encerrar as discussões em torno da formação de estudantes de medicina durante o módulo de obstetrícia e as suas interações dentro dos campos de prática, mas, principalmente, possibilitar que novas pesquisas aprofundem, por exemplo, a contribuição da antropologia para a formação da prática médica.

Por fim, considera-se que este relato proporciona a troca de aprendizagens, bem como a divulgação de ações que apontam para um novo caminho plural na formação dos estudantes de medicina.

\section{Referências}

ALONSO, Danielle. Violência Obstétrica: Conceituações E Considerações Sobre Sua Implicação No Parto. Trabalho de Conclusão de Curso (Graduação em Psicologia)- Universidade Federal Fluminense, Instituto de Ciências Humanas e Sociais, Volta Redonda, 2018. Disponível em https://app.uff.br/riuff/bitstream/1/7372/2/ Danille\%20Alonso\%20-\%20TCC.pdf. Acesso em: 10 fev. 2019.

AYRES, José Ricardo C. M. Uma Concepção Hermenêutica de Saúde. PHYSIS: Rev. Saúde Coletiva, Rio de Janeiro, 17(1):43-62, 2007. Disponível em http://www.scielo.br/pdf/physis/v17n1/v17n1a04.pdf. Acesso em: 10 fev. 2019.

BARBOSA, Murillo; HERCULANO, Thuany; BRILHANTE, Marita; SAMPAIO, Juliana. Doulas como dispositivos para humanização do parto hospitalar: do voluntariado à mercantilização. Revista Saúde e debate, Rio de Janeiro, 42(117): 420-429, 2018. Disponível em: http:// www.scielo.br/pdf/sdeb/v42n117/0103-1104-sdeb-42-117-0420.pdf. Acesso em 19 out. 2019.

BECKER, Howard. Outsiders: études en sociologie de la déviance. Paris, Métailié, 1985.

BRASIL. Resolução CNE/CES 3/2014. Diário Oficial da União, Brasília, 23 de junho de 2014 - Seção 1 - pp. 8-11. Disponível em: http:// www.fmb.unesp.br/Home/Graduacao/resolucao-dcn-2014.pdf. Acesso em: 10 fev. 2019. 
CARNEIRO, Rosamaria G. Cenas de parto e políticas do corpo: uma etnografia de práticas femininas de parto humanizado. Tese de doutorado em Ciências Sociais, Universidade Estadual de Campinas. Campinas, 2011.

LOPES, AA. Medicina Baseada em Evidências: a arte de aplicar o conhecimento científico na prática clínica. Rev Ass Med Brasil 2000; 46(3): 285-8. Disponível em: http://www.scielo.br/pdf/\%oD/ramb/ v46n3/3089.pdf. Acesso em: 13 de outubro de 2019.

GUIMARÃES , Liana Barcelar E. et al. Violência obstétrica em maternidades públicas do estado do Tocantins. Revista Estudos Feministas, Florianópolis, 26(1): 43278, 2018. Disponível em: http:// www.scielo.br/pdf/ref/v26n1/1806-9584-ref-26-01-e43278.pdf

GOMES, Samara Calixto et al. Renascimento do parto: reflexões sobre a medicalização da atenção obstétrica no Brasil. Rev. Bras. Enferm.,Brasília , v. 71, n. 5, p. 2594-2598, out. 2018. Disponível em $<\mathrm{ht} \mathrm{t} \mathrm{p} \mathrm{:} \mathrm{/} \mathrm{/} \mathrm{w} \mathrm{w} \mathrm{w.} \mathrm{s} \mathrm{c} \mathrm{i} \mathrm{e} \mathrm{l} \mathrm{o.b} \mathrm{r} \mathrm{/} \mathrm{s} \mathrm{c} \mathrm{i} \mathrm{e} \mathrm{lo.p} \mathrm{h} \mathrm{p} \mathrm{?}$ script=sci_arttext\&pid=So034-71672018000502594\&lng=pt\&nrm=iso $>$. Acesso em: 10 fev. 2019.

MALHEIROS, Paolla A. Parto e nascimento: saberes e práticas humanizadas. Texto Contexto Enferm, Florianópolis, 2012; 329-337p. Disponível em: http://www.scielo.br/pdf/tce/v21n2/a10v21n2. Acesso em: 08 de fevereiro de 2019.

MOURA, Cristina Patriota de. Outsiders: estudos de sociologia do desvio. Mana, Rio de Janeiro , v. 15, n. 2, p. 588-591, Oct. 2009. Disponível em < http://www.scielo.br/scielo.php? script $=$ sci_arttext\&pid=So104-93132009000200011\&lng $=$ en $\& n r m=i s o$ >. Acesso em: 10 Feb. 2019.

PALHARINI, Luciana Aparecida. Autonomia para quem? O discurso médico hegemônico sobre a violência obstétrica no Brasil. Cadernos pagu (49), 2017:e174907. Disponível em http://www.scielo.br/pdf/cpa/ n49/1809-4449-cpa-18094449201700490007.pdf. Acesso em: 10 Feb. 2019.

PEREIRA , Raque 1 da Rocha; FRANCO , Selma Cristina; BALDIN, Nelma. A Dor e o Protagonismo da Mulher na Parturição. Rev Bras Anestesiol 2011; 61: 3: 376-388. Disponível em: http://www.scielo.br/ pdf/rba/v61n3/v61n3a14.pdf Acesso em: 10 Feb. 2019. 
PORTELA, Jaqueline C. "Não me obriguem a um parto normal": concepções de corpo e direito de escolha de mulheres gestantes que optam pela cesárea eletiva. Trabalho apresentado na $30^{\text {a }}$ Reunião Brasileira de Antropologia. João Pessoa, 2016.

RODRIGUES, D. P. A Violência Obstétrica No Contexto Do Parto E Nascimento. Rev enferm UFPE on line., Recife, 12(1):236-46, jan., 2018. Disponível em: https://periodicos.ufpe.br/revistas/revistaenfermagem/ article/viewFile/23523/26086

ROCHA, Everardo P. Pensando em partir. In: ROCHA, Everardo P. Guimarães. O que é etnocentrismo. 5. ed. São Paulo: Editora Brasiliense, 1988. Cap. 1. p. 5-10.

TORNQUIST, Carmen S. Parto na contemporaneidade: perspectivas antropológicas. Periódicos UFPR, 2006. Disponível em: https:// periodicos.utfpr.edu.br/cgt/article/viewFile/6146/3797. Acesso em: o8 de fevereiro de 2019.

UFBA [UNIVERSIDADE FEDERAL DA BAHIA]. Projeto político pedagógico Curso de graduação em medicina. Vitória da Conquista, agosto de 2015.p.212. Disponível em: http://www.ims.ufba.br/sites/ ims.ufba.br/files / documentos / Projeto-Pol\% C3\%ADticoPedag\%C3\%B3gico1.pdf. Acesso em: o8 de fevereiro de 2019.

VENDRÚSCOLO, Cláudia Tomasi; KRUEL, Cristina Saling. A História Do Parto: Do Domicílio Ao Hospital; Das Parteiras Ao Médico; De Sujeito A Objeto. Disciplinarum Scientia. Série: Ciências Humanas, Santa Maria, v. 16, n. 1, p. 95-107, 2015. Disponível em: https:// www.periodicos.unifra.br/index.php/disciplinarumCH/article/viewFile/ 1842/1731. Acesso em: o8 de fevereiro de 2019.

VITÓRIA DA CONQUISTA. Lei $N^{o}$ 2.228, de o4 de junho de 2018. Diário oficial Vitória da Conquista - Bahia. Ano 11 Edição 2.140, quinta o7 de junho de 2018, p.96. Disponível em: https://dom.pmvc.ba.gov.br/ diarios/previsualizar/q9jMGmNW/96 


\section{Contributions of Anthropology for Training Students of Medicine during the Obstetric Module}

ABSTRACT: This experience report aims to contribute to a reflection about the context of training in obstetrics, as an integral part of medical graduation, instigated in the light of the introduction of anthropology in the learning process. To achieve this goal, it was decided to split this article into sections. The first one dealt with the process of insertion of anthropology during the training of medical students in the semester that has as Conception and Birth Thematic Axis, reflecting on the challenges involved in learning to relativize practices that are based on Evidence Based Medicine. Subsequently, in a second section, she will discuss the reflections raised by an experience lived during practical activity with a group of women activists facing the cause of humanized childbirth and active motherhood. Finally, in a last section, the possibility of a reorientation of the look on the cultural aspects that involve conception, birth, woman and her body.

KEYWORDS: Obstetrics. Higher Education. Health manpower. Anthropology. Humanizing delivery.

Fernanda Beatriz MACIEL

Bacharela em Saúde pela Universidade Federal Bahia, Instituto de Humanidades, Artes e Ciências Professor Milton Santos e graduanda em medicina pela Universidade Federal da Bahia, Instituto Multidisciplinar em Saúde.

Hebert Luan Pereira Campos dos SANTOS

Bacharel em Saúde pela Universidade Federal Bahia, Instituto de Humanidades, Artes e Ciências Professor Milton Santos e graduando em medicina pela Universidade Federal da Bahia, Instituto Multidisciplinar em Saúde.

Paulo Rogers FERREIRA

Professor Adjunto no Instituto Multidisciplinar em Saúde da Universidade Federal da Bahia. Doutor em Antropologia pela Université Laval, Canadá (2016), onde foi bolsista do Canadian Centre for Health and Safety in Agriculture (CCHSA) com sede na University of Saskatchewan, Canadá.

Recebido em: 25/o2/2019

Aprovado em: 26/12/2019 